\title{
A Balancing Act: Working and Caring for a Child with Cancer
}

\author{
Sofia K. Hjelmstedt $\mathbb{D}^{1} \cdot$ Ulla M. Forinder ${ }^{2}$ Annika M. Lindahl Norberg ${ }^{3,4} \cdot$ Emma I. M. Hovén ${ }^{1}$
}

Accepted: 1 June 2021 / Published online: 26 June 2021

(c) The Author(s) 2021

\begin{abstract}
Parenting a child with cancer creates numerous additional care demands that may lead to increased difficulties in balancing work and family responsibilities. Still, there is limited knowledge of how parents cope with both parenthood and paid work after a child's cancer diagnosis. The aim of the study was to explore mothers' and fathers' experiences of balancing the dual roles of work and parenthood following a child's cancer diagnosis. Nine focus groups with in total 32 parents of children with cancer in Sweden were conducted. The data was analysed using qualitative content analysis. Three categories were identified: Shifts in the importance of the parent role and the work role, Influence of context and conditions on the balance of roles, and Long-term unbalance of roles. Parents expressed an increased appreciation of time spent with family, but also emphasized the importance of work to counterbalance the sometimes overwhelming parenting demands. The pre-existing financial situation, work situation, and employer behaviour were important factors influencing the parents' ability to balance work and family. Traditional gender roles influenced how couples divided responsibilities and reflected on their experiences. Mothers and fathers were also met with different expectations, which highlights the need for the healthcare to consider their communication with caregivers. Importantly, the parents expressed how the child's illness affected their ability to balance work and family for a long time, while the understanding and support from others had steadily declined. Enabling parents to care for their ill child without sacrificing their own career is of utmost importance, and future research should focus on identifying which factors facilitate for parents to achieve a sustainable work-life balance.
\end{abstract}

Keywords Childhood cancer $\cdot$ Childcare $\cdot$ Work family balance $\cdot$ Parents $\cdot$ Gender

\section{Highlights}

- Parents cherish time with family even more after the child's illness, but also emphasize the importance of work to counterbalance the parenting demands.

- Characteristics of the work environment play a highly influential role in parents' ability to manage the work-family balance.

- Traditional gendered division of parenting and working increased after the child's illness.

- Different experiences between mothers and fathers highlight the importance for the healthcare to consider their communication.

- Difficulties with balancing work and family remain for a long time, while understanding and support from others decrease with time.

Sofia K. Hjelmstedt

sofia.hjelmstedt@ki.se

1 Department of Women's and Children's Health, Karolinska Institutet, Stockholm, Sweden

2 Faculty of Health and Occupational Studies, University of Gävle, Gävle, Sweden
3 Centre for Occupational and Environmental Medicine, Stockholm County Council, Stockholm, Sweden

4 Institute of Environmental Medicine, Karolinska Institutet, Stockholm, Sweden 
When a child is diagnosed with cancer, the whole family is affected. For the parents, increased caregiving demands and the experience of psychological distress may lead to difficulties in balancing work and family responsibilities. More than 300 children are diagnosed with cancer each year in Sweden, and it is one of the most common causes of death among Swedish children (National Board of Health and Welfare, 2018). The treatment of childhood cancer varies in both modality and duration depending on type of cancer. For the most common type of childhood cancer, acute lymphoblastic leukemia, the treatment is typically two and a half years. The 5-year survival rate in Sweden is approximately 85\% (National Board of Health and Welfare, 2018), but survivors are often subject to a range of adverse late effects (i.e. health problems that occur after the active cancer treatment has ended), such as neurocognitive, musculoskeletal, and psychological problems (Oeffinger et al., 2006). Parenting a child with cancer thus creates numerous additional care demands even long after end of treatment, but further knowledge of parents' ability to balance work and parenthood after a child's cancer diagnosis is still warranted (Wakefield et al., 2014). This knowledge is necessary in order to improve the psychosocial support provided to parents.

Compared to parents of healthy children, parents of children with a chronic illness, including cancer, have been found to endorse greater parenting stress, i.e. stress related to the role as parent (Cousino \& Hazen, 2013; Pinquart, 2017). In addition, parenting a chronically ill child may lead to difficulties in coping with responsibilities related to paid work. Studies have shown reductions in employment and work absenteeism, along with difficulties with unsupportive employers and finding flexible jobs (Kish et al., 2018). Parents of children with cancer have been found to experience high levels of psychological distress, including symptoms of anxiety, depression, and posttraumatic stress, throughout the child's treatment. Although the level of distress decreases with time after diagnosis, a substantial subgroup of parents report persistent distress (Ljungman et al., 2015; Michel et al., 2020; Vrijmoet-Wiersma et al., 2008; Wikman et al., 2018). Parents have also been shown to experience substantial socioeconomic consequences as a result of the child's cancer, including income losses, work disruptions and increased out-of-pocket expenses (Roser et al., 2019; Santacroce et al., 2018). The importance of financial hardship on parents' psychosocial well-being has been emphasized in later years. Today, assessment of financial burden throughout the disease trajectory is considered an important part of psychosocial support for childhood cancer families (Pelletier \& Bona, 2015).

Having to care for a chronically ill child has been shown to be a risk factor for the onset of work-family conflict (Jansen et al., 2003). A work-family conflict occurs when the role pressures from the domains of work and family are mutually incompatible, resulting in an interrole conflict (Greenhaus \& Beutell, 1985). When the pressure of a role increases, the limited resources of an individual, such as time, can lead to role overload and an inability to fulfil the demands of other roles, thus resulting in a conflict, either in the direction of work interfering with family, or family interfering with work (Greenhaus \& Beutell, 1985). Parents of seriously or chronically ill children have reported great difficulties in balancing the expectations of being fully committed to work, while still having to struggle with responsibilities at home (Brown \& Clark, 2017; George et al., 2008; Kish et al., 2018). Still, however, there is a gap in the literature on perceptions of roles and implications of potential role conflicts among parents of seriously or chronically ill children (Kish et al., 2018), including how the work-family balance is experienced by parents of children with cancer (Wakefield et al., 2014).

In the existing studies, parents of children with cancer have reported difficulties in combining work with caring for the ill child, as well as for others in the family, due to significant disruptions in the everyday life (Granek et al., 2012; Long \& Marsland, 2011; Molinaro \& Fletcher, 2018; Peikert et al., 2020; Wakefield et al., 2014). Parents of children with cancer have to reorganize roles and responsibilities for childcare and work, with mothers often taking primary responsibility of the ill child (Clarke et al., 2009; Long \& Marsland, 2011; Molinaro \& Fletcher, 2018). The most pronounced changes in role reorganization usually takes place during the initial stages of diagnosis and early treatment (Long \& Marsland, 2011), although difficulties in managing the increased caregiving demands may last longterm (Peikert et al., 2020). High levels of caregiving stress have been reported by parents of children with cancer (Rodriguez et al., 2012), which in turn have been found to associate with impaired parental functioning (Sulkers et al., 2015). Childhood cancer creates a number of new caregiving tasks that parents have to take on (Granek et al., 2012). Parents may have to adapt to a number of new roles, such as being a medical assistant, teacher or therapist (Lindahl Norberg \& Steneby, 2009), further complicating the balance of different life roles. Still, to gain increased understanding of the impact of childhood cancer on family life, studies that explore parents' experiences of the challenges related to work and family are needed. With this study, we wanted to capture the experiences that are more commonly shared by parents of children with cancer, without restricting the research to, for example, mothers (Molinaro \& Fletcher, 2018), single parents (Granek et al., 2012) or parents of survivors (Peikert et al., 2020).

The ability to balance work and family when a child is diagnosed with cancer may partly depend on access to available healthcare and support system, and research from different contexts are needed to compare experiences of 
families (Wakefield et al., 2014). In Sweden, the governmental welfare policies are designed to enable parents with seriously ill children to be present as full-time caregivers without having to sacrifice their employment, as well as be reimbursed for much of the both direct and indirect costs. Parents who have to care for a seriously ill child can apply for childcare benefits for an unlimited number of days, as well as sickness benefits due to their own ill health, which both constitute almost $80 \%$ of an individual's salary, up to an income ceiling (Social Insurance Code, 2010a, b). Although parents of children with cancer in Sweden experience adverse effects on income from employment, employment and work ability (Hjelmstedt et al., 2017; Lindahl Norberg et al., 2017), the available social benefits appear to ease the financial burden (Hiyoshi et al., 2018). Consistent with findings from other countries (Roser et al., 2019; Santacroce et al., 2018), the adverse effects have been found to be more pronounced among mothers than fathers in Sweden (Hiyoshi et al., 2018; Hjelmstedt et al., 2017; Lindahl Norberg et al., 2017). Even with the mitigating effect of welfare policies on the financial situation, parents have been found to report a need for more psychosocial support (Kukkola et al., 2017). In the view of the distress of parents, which may persist after end of child's treatment, together with the fact that many survivors experience late effects, it is warranted to learn more of how this affects the parents' ability to combine work and parenthood, despite an extensive public support system such as the one in Sweden.

\section{Aim}

The impact of child's serious and/or chronic illness on the balance between work and family warrants more research (Kish et al., 2018), including the situation for parents of children with cancer in various contexts (Wakefield et al., 2014). The major disruption of everyday life that follows a child's cancer diagnosis may be significantly challenging, and considering that parents constitute the most important informal caregivers for children with cancer, it is important to understand the experiences of combining work and parenthood when the demands of caregiving increase.

The aim of the study was to explore mothers' and fathers' experiences of balancing the dual roles of work and parenthood following a child's cancer diagnosis.

\section{Methods}

\section{Procedure}

The study is based on interview data from focus groups. Focus groups were considered an appropriate method, as it enables interaction and let participants use others' experiences to reflect on their own experiences (Morgan, 1997). A purposeful sampling of participants was used. The inclusion criteria were: (1) Being a parent of a child who has or have had cancer, and (2) Swedish-speaking, as the focus groups were conducted in Swedish. We aimed to capture a range of experiences from parents with varying socioeconomic, demographic and child illness related characteristics, and the focus was to attain rich data rather than to achieve data saturation. The participants were recruited via the Swedish Childhood Cancer Fund through advertisement on their official web page, Facebook page, and newsletters, and by presenting the study at their national and regional annual meetings. Additional recruitment was conducted by participants recommending other potential participants. Those who showed interest were given written information about the study along with an invitation to participate in a focus group.

Each focus group consisted of 2-5 participants, a moderator and an observer. Authors 'SH, UF and ALN' divided the roles of moderator and observer. The purpose of the observer was to support the moderator in ensuring that the discussion covered all themes related to the aim of the study, and that all participants were given the chance to talk. The interviews took place in conference rooms either at hotels or at the authors' office, depending on what location was most convenient for the participants. Three mothers and two fathers participated via video link.

The focus groups began with the moderator repeating the purpose of the study and emphasizing that the intention of the focus group was to let the participants share experiences and discuss with each other. The moderator thereafter asked open-ended questions based on the themes of the study. The discussion focused on parents' work situation before and after diagnosis, their work ability and possibility to return to work, how care responsibilities were divided within in a couple, and the psychosocial support they received both during the child's active treatment and after end of treatment or the child's death. Examples of the questions asked are: "How was your work situation affected by the child's cancer"? and "How did you and the other parent divide childcare responsibilities". Presenting results from registrybased studies previously conducted by the authors ('Lindahl Norberg et al., 2017') were used as prompts, with the purpose of the participants reflecting on gender differences in the results based on their own experiences.

\section{Participants}

Nine focus groups were conducted, with in total 21 mothers and 11 fathers. The groups were homogeneous and contrasting in terms of sex, i.e. six groups consisted of only mothers and three groups consisted of only fathers. The groups were heterogeneous in relation to other 
sociodemographic and illness-related factors. Characteristics of the participants are presented in Table 1. All participants were part of a different-sex parental couple, and varied regarding whether they were still with the other parent of the child or not. Three parental couples were represented by both parents.

\section{Analysis}

The data consisted of $17 \mathrm{~h}$ and $15 \mathrm{~min}$ of recorded interview data, with an average of $1 \mathrm{~h}$ and $55 \mathrm{~min}$ per focus group. The focus groups were audio-recorded, transcribed verbatim and analysed using qualitative content analysis (Graneheim \& Lundman, 2004). The process was collaborative, with individual and group analysis being conducted back and forth. The analysis began by reading through the transcripts to get a sense of the whole (by authors 'SH and EH'). Meaning units, which were sentences or paragraphs that related to the aim of the study, were highlighted by 'SH and EH' separately, and thereafter compared and discussed to reach agreement. The meaning units were then extracted into codes by 'SH and $\mathrm{EH}^{\prime}$ separately, compared, and discussed to reach agreement. The codes were thereafter abstracted and grouped by 'SH and $\mathrm{EH}$ together. The coding was conducted using the software NVivo, Version 12. Discussion between all authors resulted in the final subcategories and categories. The content analysis process is presented in Table 2 .

\section{Results}

At the time of the child's diagnosis, parents described how their life was shaken to the core. Both mothers and fathers expressed that fulfilling the parent role became the only thing that mattered. There was little room to reflect on either work or their own well-being. After this initial reaction with complete focus on the child, parents had to combine the care of the child with other important aspects of their life. Participants described how the child's cancer diagnosis had disrupted their life situation, affecting the balance of the roles of work and parenthood both during the more acute phase of diagnosis and active treatment, but also in the long-term. The analysis of these experiences resulted in three categories and seven subcategories (Fig. 1), which are presented below.

\section{Shifts in the Importance of the Parent Role and the Work Role}

This category includes descriptions of how the experience of having a child diagnosed with cancer changed how the parents viewed the importance of their parent role and work role, as well as descriptions of a need for a continued balance between work and family despite a new life situation.

\section{Changed perspectives and priorities}

Parents reported having had reflected on the meaning of being a working parent, with changed perspectives on how one should juggle career and family life. Even though family came first even before the child's illness, they described that their priorities were clearer now. The idea of not wasting their life on working was emphasized, as was an understanding of life as fleeting and that it can change radically at any point. Parents who had worked during the child's treatment, sometimes due to lack of understanding of the seriousness of the illness, expressed regret and reflected on how they would not have made the same choices if anything similar happened again.

"I feel like what has really happened to me, my career and my economy, it's that you don't know how long you'll live, how long your child will live. And I will never, I will never work full time again, no way". (Mother of child off active cancer treatment, focus group 1)

Parents furthermore described how they had evolved as parents, that the experience had made them better parents. They described this in terms of being more present for their children and engaging more in their lives. The changes were however not all positive. Parents also described how they were constantly worried for their children, even long after end of treatment.

\section{"Intellectually, I've always known that parenthood} means having to worry. But now I know. About being scared, constantly. All the time". (Bereaved mother, focus group 5)

When at work, parents described how they had been better at saying no, and not taking on too much. In addition, parents described a change in their own view of what their professional work should consist of, such as making their work life count and doing something that matters. For some this meant changing career, for example to work in healthcare or with children with special needs.

"Already after a year or so, after he got ill, I felt that this is what I want to work with. In health care.

I don't want to do something to generate money, I want to work with people and help out. And then I gave my son palliative care. Around the clock, the last three months of his life. And that's when I got interested in working with that. Emergency care or palliative care... when it really matters. Where you can make a difference". (Bereaved father, focus group 4) 
Table 1 Characteristics of the focus group participants $(n=32)$ in focus groups $(n=9)$, assessed at time of interview.

\begin{tabular}{|c|c|c|}
\hline Parent characteristics & No. & $\%$ \\
\hline \multicolumn{3}{|l|}{ Sex } \\
\hline Women & 21 & 65.6 \\
\hline Men & 11 & 34.4 \\
\hline \multicolumn{3}{|l|}{ Education } \\
\hline Basic & 1 & 3.1 \\
\hline Secondary & 9 & 28.1 \\
\hline Post-secondary less than 3 years & 3 & 9.4 \\
\hline Post-secondary more than 3 years & 18 & 56.3 \\
\hline Other/missing & 1 & 3.1 \\
\hline \multicolumn{3}{|l|}{ Employment situation } \\
\hline Full-time & 15 & 46.9 \\
\hline Part-time & 7 & 21.9 \\
\hline Self-employed & 2 & 6.3 \\
\hline Sick leave & 2 & 6.3 \\
\hline Unemployed & 2 & 6.3 \\
\hline Other/missing & 4 & 12.5 \\
\hline \multicolumn{3}{|l|}{ Area of residence ${ }^{\mathrm{a}}$} \\
\hline Cities & 16 & 50 \\
\hline Towns and suburbs & 10 & 31.2 \\
\hline \multirow[t]{2}{*}{ Rural areas } & 6 & 18.8 \\
\hline & Median & Range \\
\hline Age, in years & 44 & $31-51$ \\
\hline Household characteristics & No. & $\%$ \\
\hline \multicolumn{3}{|l|}{ Household type } \\
\hline Living with child's other parent & 23 & 71.9 \\
\hline $\begin{array}{l}\text { Living with other adult than } \\
\text { child's other parent }\end{array}$ & 2 & 6.3 \\
\hline Single & 5 & 15.6 \\
\hline Other/missing & 2 & 6.3 \\
\hline \multicolumn{3}{|l|}{ Custody of child } \\
\hline Shared with other parent & 30 & 93.8 \\
\hline Single custody & 2 & 6.3 \\
\hline \multicolumn{3}{|l|}{ Siblings to the child with cancer } \\
\hline Yes & 30 & 93.8 \\
\hline No & 2 & 6.3 \\
\hline Child characteristics & No. & $\%$ \\
\hline \multicolumn{3}{|l|}{ Diagnosis } \\
\hline Leukaemia & 13 & 40.6 \\
\hline Central nervous system tumours & 8 & 25.0 \\
\hline Lymphoma & 4 & 12.5 \\
\hline Other & 7 & 21.9 \\
\hline \multicolumn{3}{|l|}{ Treatment status } \\
\hline Under treatment & 5 & 15.6 \\
\hline Active cancer treatment completed & 18 & 56.3 \\
\hline
\end{tabular}

Table 1 (continued)

\begin{tabular}{lcc}
\hline Child characteristics & No. & $\%$ \\
\hline Deceased & 9 & 28.1 \\
Parent's assessment of child's health & & \\
Excellent & 4 & 12.5 \\
Very good & 9 & 28.1 \\
Good & 5 & 15.6 \\
Not so good & 3 & 9.4 \\
Bad & 1 & 3.1 \\
Not applicable/missing & 10 & 31.2 \\
& Median & Range \\
Age at time of diagnosis, in years & 5 & $0-15$ \\
Age at study, in years & 12 & $1-20$ \\
(survivors only) & & $1-16$ \\
Time since diagnosis, in years & 5 &
\end{tabular}

${ }^{a}$ According to Eurostats description of Degree of Urbanisation (DEGURBA)

\section{Work as a positive counterbalance to the parent role}

Despite the parents' emphasis on the importance of family life, they also expressed a feeling of being trapped in the parent role following the child's diagnosis. Although the parents described how they wanted to be with their child, they also talked about the need of a break, i.e. to talk about 'ordinary things', think of something else and be someone else than the parent of a child with cancer. Parents described how work had become a source for such positive affirmation. It provided a context for social interaction and support, as well as an opportunity to focus on something else and be treated as professionals.

"Like a breath of fresh air, so to speak. To be in a normal situation where you can spend time with other people and talk about other things". (Bereaved father, focus group 8)

Being at work was not only considered important as it served as a contrast to caring for the child, but the work role was also emphasised by some parents as a big part of who they are and something that they cherished also before the child's cancer diagnosis.

\section{Influence of Context and Conditions on the Balance of Roles}

This category concerns descriptions relating to the importance of the context that the parents' acted within, and how their pre-existing conditions influenced the situation. 


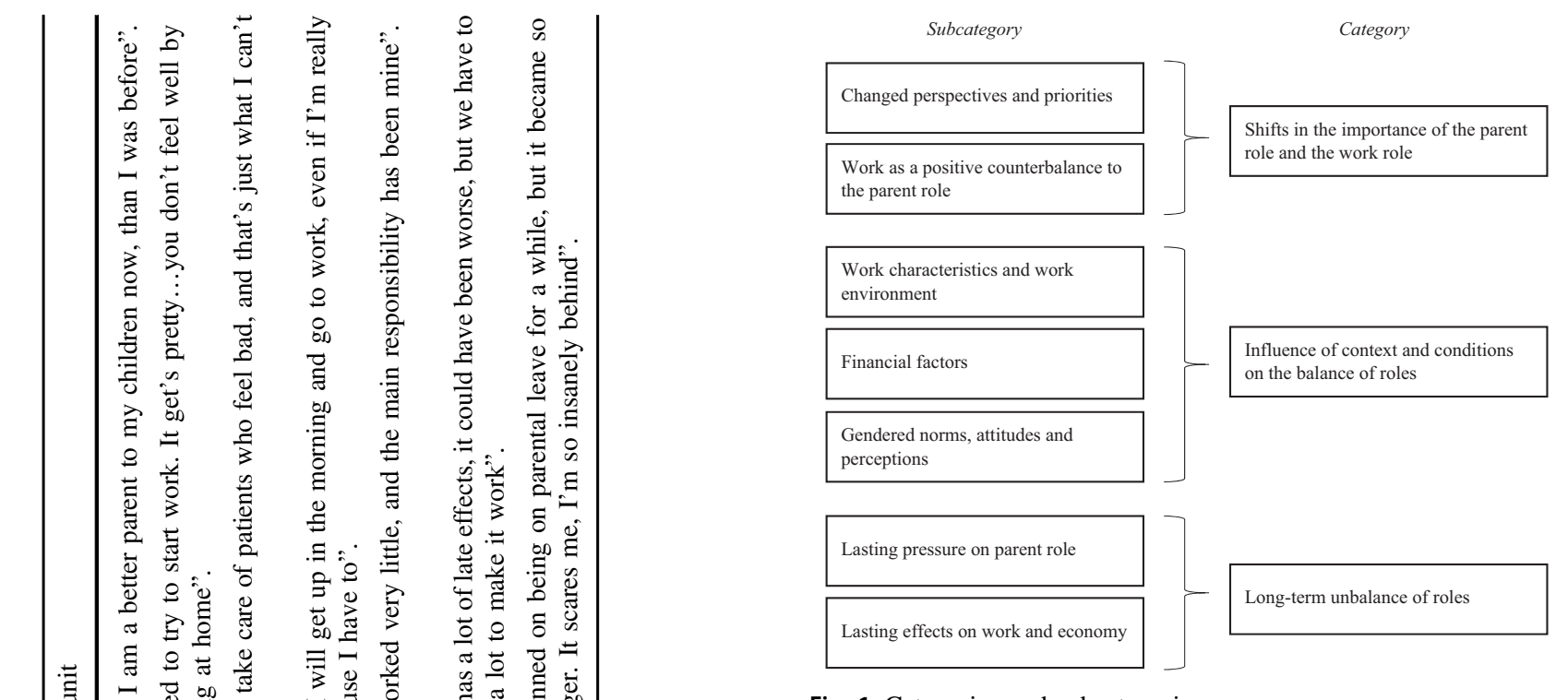

Fig. 1 Categories and subcategories

\section{Work characteristics and work environment}

Type of job was described as important for the ability to manage work life. Those who had more emotionally or socially demanding jobs, such as teaching or working in healthcare, related difficulties in balancing the demands at work and home to the type of job they had. For example, parents described difficulties in behaving as sympathetically as they wanted to when they were faced with other people's problems at work, comparing the others' problems with their own. Type of job was also discussed as a factor affecting how parents divided responsibilities for work and childcare within couples, such as fathers having jobs that were more flexible and therefore being able to return to work earlier or to a greater extent than the mothers did.

\section{"I needed more time to readjust because my job demands more of me as a person than what my husband's job did. He could go in and sit down at the office and read the newspaper. And to his boss, that was okay. But my job demands so much of me as a person". (Mother of child off active cancer treatment, focus group 1)}

When being absent from work, parents still described difficulties in completely detaching themselves from work. This was related to both their own willingness to stay connected to their work place, but also to a fear of neglecting their careers if they detached completely. Another issue affecting the parents' ability to prioritize their time as they wanted was a sense of loyalty to the employer and feeling bad for not being able to perform as expected at work. 
"Now I have to be home to care for my sick child again. So it's always there in the back of my mind, now I'm messing things up for my colleague or for my boss or something”. (Father of child under treatment, focus group 4)

The work environment and the attitude of the employer was mentioned as crucial for maintaining balance between work and parenthood. Having an understanding employer and flexible work arrangements made it possible for some to adjust their work and hence sustain a balance. Some fathers even described how they did not need to take a leave of absence, but could keep their full salary without actually working at all, for a period of time, or working significantly less.

"And I have a very free work so my employer gave me many months of... low work demands. I work from home anyway, but I haven't produced what I should. But they let me have that". (Father of child off active cancer treatment, focus group 2)

On the contrary, others related difficulties with unsympathetic employers. Parents described employers who were not interested in accommodating to the parents' changed circumstances, forcing them to sacrifice their career prospects in order to be able to be there for their child. Some parents even described losing their job because they could not live up to the expectations of their employer.

\section{Financial factors}

The ability to balance work and family was affected by financial factors and the pre-existing financial situation of the family. Some described that they would have chosen to focus entirely on their child if they could, but that remaining in or returning to work as soon as possible was unavoidable in order to manage family finances.

\section{"The bills don't stop coming just because something like this happens to you. We had loans on the house, I mean, gas and electricity and everything else. Plus two other kids who had to get theirs, who still had to get some kind of normal life. You wanted them to have it like it was before". (Mother of child off active cancer treatment, focus group 9)}

Parents also described how their reduced income inconveniently coincided with more expenses related to the child's illness. Furthermore, being forced to go back to work earlier than desired was not only described by those who had strained finances in beforehand, but also by parents who had a high income, but who had expenditures that required them to keep a high income.
"It came as a shock. Because we both had salaries above the income ceiling [in the social insurance scheme]. So we both got half of what we usually get. That's a real punch, you know". (Mother of child off active cancer treatment, focus group 6)

Financial factors, such as fathers having a higher income, was discussed as a reason for fathers to remain in work or return to work earlier than mothers.

"We made a purely economic decision when we looked it over. Who will we lose most from. And used that as basis really. That was really what our decision was grounded on". (Father of child off active cancer treatment, focus group 4)

Parents described how the support systems, such as public and private insurances, health care services, as well as financial support from friends and families, enabled them to focus on caring for the child instead of work. The experiences of support from the welfare system varied. Some experienced a smooth process, while others described it as a struggle that created even more stress on the family. As many parents had to take leave from work from one day to another, dealing with related practical matters, such as applying for financial benefits, became a stressful inconvenience, adding to the stress of coping with the child's illness.

\section{Gendered norms, attitudes and perceptions}

The parents discussed that being a mother or a father impacted the opportunities to balance work and parenthood. Besides work characteristics and financial factors, differences in how mothers and fathers divided responsibilities for work and caring were discussed as a result of mothers and fathers being different. Individual different personality traits within a couple was discussed, but parents also reflected on fundamental or 'natural' differences between men and women.

"Me and [the father] were very different. I reacted, I got this blow to the head when we got the news, I had tunnel vision. I was like, I became this lioness, I'm going to rescue my child. The whole world just disappeared". (Mother of child off active cancer treatment, focus group 1)

Parents also described that they divided their time with the child based on who the child was more attached to, which often was the mother. How the parents had balanced the demands from work and parenthood was also affected by expectations and reactions from others. It was described 
that they were met with expectations of mothers being the primary caregivers, in particular by the hospital staff but also from other people around them.

"Personally, I got the feeling that the healthcare is affected by that too. I experienced at the hospital that there is kind of a preconception that [the mother] is one hundred percent on childcare leave. That I was there when I could, sort of". (Father of child off active cancer treatment, focus group 4)

Parents also described that they were met with different expectations of how to react and behave in a situation of crisis, with fathers not being given as much room for emotions and grief.

"[The father] and [the child] were so close, but it was still me who had priority in grieving. That's how I think he feels, that he did not get the place he deserved really". (Bereaved mother, focus group 5)

Even though many parents experienced that people around them had been supportive if they wanted to work while the child was ill, mothers described experiences of being questioned in their choices differently than fathers.

\section{"And I have gotten the question 'God, are you really going to work?' I don't think anyone has ever said that to [the father]. I don't think they ever asked why he's at work". (Bereaved mother, focus group 5)}

Although parents experienced being met with expectations of traditional divisions of responsibilities for work and family, mothers also described the opposite, such as people looking down at them for being at home with the child more than the father, and they expressed a fear of being perceived as 'housewives'.

\section{Long-Term Unbalance of Roles}

This category includes experiences of how the child's cancer was present in the parents' life even long after end of treatment or child's death, by still having a major impact on their ability to balance work and parenthood.

\section{Lasting pressure on parent role}

Parents described many obstacles for the entire family to cope with when the child's cancer treatment was over, and that the demands of the parent role were often overwhelming. Parents, in particular mothers, described how their own health had been impaired since the child's illness. The experience of caring for a child with cancer, and in some cases losing a child to cancer, had left many with a reduced work capacity due to for example fatigue, lack of resistance to stress, and body ache. They expressed an insight of never being able to get back to their full capacity.

"I feel like I can't take a job right now. I mean, I wouldn't manage. Particularly not my body. The least bit of stress..." (Mother of child off active cancer treatment, focus group 1)

Parents described that it was often after the end of the child's treatment that the consequences for themselves caught up with them, when having the time to consider their own well-being, or lack thereof. The treatment was over, but the worry for the child's health remained and affected them. Parents described being particularly overwhelmed with worry when it was time for check-ups, and that they were often unable to perform at work during those times.

"Every time we get this notice, 'now it's time for your check-up', the heart stops, every time. Even if he never had a relapse, he has always been fine. The worry is still there. What if"? (Mother of child off active cancer treatment, focus group 9)

Parents also described how the children were affected by late effects and poor health, which had a large impact on the caregiving burden and hence on the parents' ability to combine the demands of parenthood with the demands at work. Not only did the parents describe how the children's ill health required them to constantly be on call, but they also experienced having to change their job in order to manage the parenting demands, such as having to get a job close to home so that they could easily and quickly be there for the child if needed.

"Because what many people don't understand is that most of the time...either she's sick the whole day or she calls me after a few hours in school and says ' $\mathrm{Hi}$ mom, you have to pick me up now'. And that's what my days are like". (Mother of child off active cancer treatment, focus group 1)

Parents also acknowledged that siblings of the ill child had been neglected during treatment, and expressed how siblings had reacted more after the end of treatment, thus creating new demands on them as parents. Another concern of parents, that added to the burden of the parent role, was how their children will cope with the rest of their life. They worried about their children suffering both physically, psychologically and socially from their cancer, and wondered what their future life will look like. 
"I just feel like this: Will he ever have a job? I got the ulcer from thinking: What's his life going to look like? I think that's tough as hell. I'm trying to think, will he ever meet someone that he wants to live with or will he be alone his whole life, because he can't even get out of bed"? (Mother of child off active cancer treatment, focus group 6)

Parents experienced that people around them became less understanding with time, with colleagues questioning their behaviour and worry. Employers had lost patience of their reduced work capacity and the lingering or new care needs of the child. Parents expressed that people expected everything to be back to normal, while the parents felt that things would never be entirely back to normal.

\begin{abstract}
"My experience is that there is a certain period of time when it's accepted to feel bad. It's okay during the treatment, then they could understand. Then, at the same day the treatment is over everything is supposed to be back to normal, then everything is supposed to be fine. 'Now it's over, everything went well! Great, he's alive!' But for us, it wasn't over. It's not over now". (Mother of child off active cancer treatment, focus group 7)
\end{abstract}

\section{Lasting effects on work and economy}

Parents' financial situation suffered from the child's illness even years after end of treatment or the child's death, which impacted their ability to balance work and family.

"I went back to working part-time to, well, to get the finances rolling so to speak, but...I still haven't recovered, after ten years, economically". (Mother of child off active cancer treatment, focus group 3)

Parents expressed a feeling of insufficient and ineffective organization of support systems. In particular, parents expressed a feeling of being left on their own after the end of treatment, even though that was the time when many new problems had arisen. Although many had been able to return to work, others described how their focus on caring for the child had forced them out of work by employers, made them fall behind in wages, and experience stalled careers.

"Sometimes I feel like, I've penalized myself at work. That's what I've done. So I'm not sure I can continue to work there./.../It's pretty obvious they want to get rid of me, I think. So it's, it's really heavy". (Mother of child off active cancer treatment, focus group 5)
Parents who had been unemployed during the child's illness expressed a fear of having been punished for being absent from the labour market for a long time. Difficulties finding a job were related to being a parent of a child with cancer, that having cared for a child with cancer was a disadvantage when applying for job due to potential lingering care needs of the child, but also that childhood cancer was a subject that people would rather not associate with at all.

Mothers described difficulties in returning to work fulltime, partly due to their own ill health. One explanation to this was mothers' greater responsibility for caring for the child during active treatment, which had left them with more emotional stress, resulting in a reduced work ability. Mothers described how they did not regret that they had prioritised caring for the child over work, but that they felt that reality had caught up with them. With time they realised what they had sacrificed in terms of career and financial stability. Worry was expressed about how their career and economy was affected in the long-term and they expressed regret of being dependent on their partner.

"We have to buy a summer house at some point, and put it in my name. If he leaves me, I get... I have no retirement pension./.../ I can only hope that [the father] sticks with me so that he can support me later". (Mother of child off active cancer treatment, focus group 7)

\section{Discussion}

This study shows that many parents do indeed struggle with balancing work and family responsibilities after a child is diagnosed with cancer. The new parenting responsibilities and increased pressure of the parent role, in particular, expose aspects of conflict by family interfering with work. The additional demands of the child's illness required time and energy that was not compatible with the ordinary demands of work, often resulting in role overload. In the work-family conflict model presented by Greenhaus and Beutell (1985), it is proposed that work-family conflict is intensified when the family and work roles are central to the person's self-concept. The parents in our study did express an intensified value of the parent role, while at the same time stressing the importance of being a professional and not 'only' a parent. Many expressed feelings of not fulfilling either of these life roles in a satisfying manner, with worries of not being able to care sufficiently for the ill child, feeling bad about neglecting the needs of siblings, but also fearing having to sacrifice their work and career, as well as feeling 
guilty of not being considered a reliable co-worker. An intensified role conflict could thus be seen as a result of the reported difficulties in living up to both their own and others' expectations at home as well as at work. These findings of parents experiencing guilt and feeling overwhelmed in their roles are reflected among parents of children with other chronic illnesses as well (Kish et al., 2020).

In addition to struggling to find a sustainable balance between different roles, the parents in this study also expressed that the child's illness had changed their view of the importance of their life roles, with the parent role making up for a larger proportion of what they perceived to be important in how they spent their time. They described how the experience of having a seriously ill child has made them better parents, and emphasized a will to be present with their children to a larger extent than before, which mirrors previous research (Kelada et al., 2020; Lindahl Norberg \& Steneby, 2009; Long \& Marsland, 2011; Peikert et al., 2020; Tan et al., 2020). A rather unexpected finding was that parents reported not only having changed their priorities in relation to the balance between the parent role and the work role, but also that the experience of caring for a seriously ill child had led some parents to re-evaluate what their work life should consist of. For example, parents expressed a will to work 'where it mattered', for example within childcare and healthcare. Similar findings of wanting to make a difference in their work life have also been found among mothers and fathers of children with cancer in Australia (Kelada et al., 2020). In the Australian study, this was reported among parents with the highest socioeconomic status (Kelada et al., 2020), a pattern that was not evident in this study.

The participants expressed that being a parent could be overwhelming and testified that the parent role at times took over their own needs and created a feeling of entrapment, from which work could serve a function of escape. Being in gainful employment is not only important in order to avoid income losses, but participation in the workforce may also offer other benefits. Benefits such as emotional well-being, self-fulfilment, companionship, as well as a break from caregiving responsibilities, have previously been found among parents of children with serious illnesses (Brown \& Clark, 2017; George et al., 2008; Kish et al., 2020; Lewis et al., 2000; Morris, 2014), including cancer (Wakefield et al., 2014). These benefits from remaining in or returning to work were emphasized by the parents in this study as well, with accounts of how work provided a platform for the parents to be someone else beyond being the parent of a child with cancer, and allowing a welcomed respite from caregiving demands. Our findings highlight that enabling parents to care for their ill child without having to sacrifice their work life is crucial. Future studies should identify how this can be achieved, and more specifically what facilitators and barriers there are to achieve a sustainable work-life balance. This includes studying the potential influence and interaction of involved actors such as governmental agencies, employers, occupational healthcare, and primary healthcare.

Parents reported influence of gender in how they individually and as a couple balanced work and parenthood. At the time of diagnosis, both mothers and fathers described how both parents had focused completely on caring for the child. A common description was that they shared the care of the child evenly in the acute phase, close in time to diagnosis. However, when they in time began to return to work, it was often the father who returned to work earlier or to a greater extent. These results are reflected in a previous registry-based study, which found no disparity in child care leave between mothers and fathers of children with cancer around the time of diagnosis, but a return to skewed division of care leave, with mothers being on more care leave than fathers, later in the disease trajectory (Hjelmstedt et al., 2021). Participants in this study reported that one reason for this was that the father had a higher income, and they decided on how to divide responsibilities for work and childcare based on what was most economically favourable for the family. This reasoning is however not consistent with previous findings concluding only a weak association between division of care responsibilities and relative income within parental couples of children with cancer (Hjelmstedt et al., 2021). Also in the general Swedish population, where the pattern consistently has displayed mothers to use the majority of a parental couple's parental and childcare leave (Statistics Sweden, 2020), have the absolute and relative income of a parent been found to be secondary in determining a parent's extent of parental leave, whereas gender has been found the most important determinant (Swedish Social Insurance Agency, 2013).

Parents, in particular the mothers, also discussed differences in responsibilities for work and family to be a result of inherent differences between men and women. Some mothers described a very strong and instinctive sense of protectiveness, and claimed that the fathers did not react with the same natural instinct. Adding to the parents' own experiences were the similar expectations from others around them. These reactions of enhanced gender-typical behaviour, and in particular the confirmation from others in regards of mothers being seen as the primary parent, could be further studied in the light of the theory of 'doing gender'. This theory suggest that gender is a feature of social situations, where men and women 'do gender' by repeated everyday interaction in a way that the actions begin to seem naturally male or female, and that if the behaviour is conducted 'appropriately' is in turn also confirmed by others (West \& Zimmerman, 1987). One could question whether 
the event of a child's serious illness pushes what is viewed as gender-appropriate parenting into a more traditional way of parenting, in terms of both the parents' own perceptions as well as the societal expectations. Patterns of reinforced traditional parenting roles among parents of ill children have been suggested in previous studies (Clarke et al., 2009; Gibbins et al., 2012; Pelchat et al., 2007). In our study, however, the mothers also expressed a feeling of being torn between fulfilling the ideal of the 'natural' mother, and the fear of being labelled 'merely a housewife', as dual-earners are the common feature in Swedish households.

Importantly, differences in how the parents were treated based on gender negatively affected both mothers and fathers. Whereas mothers were particularly burdened with expectations of caregiving and fulfilling a considerable parent role, the fathers' parent role were in some cases reduced or overlooked by others. Notably, parents expressed that the healthcare staff still treated the mother as the primary caregiver, making fathers feeling left out. In addition, fathers were described as having less access to emotional support, from both personal support and welfare systems. Previous research has found that fathers' sense of pressure to take the breadwinning role when a child is treated for cancer may cause both financial trauma and consequential psychological distress (Santacroce et al., 2020). Our study suggests that despite the progress of gender equality in many aspects of society the past decades, mothers and fathers are still met with different expectations when it comes to parenting a seriously ill child, even in a country such as Sweden, where gender equality has been extensively advocated. Importantly, our results suggest that the Swedish healthcare need to reflect on their communication and care of patients and caregivers to ensure that everyone is treated equally based on sex, as well as other characteristics.

The increased burden of the parent role that the mothers, in particular, expressed, can be reflected in quantitative studies. Previous findings conclude that Swedish mothers', but not fathers', work status is affected by a child's cancer for several years after diagnosis (Lindahl Norberg et al., 2017), and that mothers are on sick leave following a child's cancer diagnosis to a larger extent than fathers (Hjelmstedt et al., 2017). Several mothers in our study expressed a severe impact on their health following the child's illness, often appearing after the child had ended treatment, which had a substantial effect on their ability to work. This delayed impact on parents' own health and subsequently their work ability is supported in previous studies (Lindahl Norberg \& Steneby, 2009). Furthermore, previous findings conclude that Swedish parents of children with cancer are reimbursed sufficiently for reduced income from work by the welfare system around diagnosis and during the first years after, but that mothers fall behind in total income after a few years (Hiyoshi et al., 2018). Our findings demonstrate that mothers bare witness to these consequences, expressed by worry about what their absence from work would mean in terms of low retirement pension, and a stalled career. What is needed to avoid forcing parents to choose between economic stability and caring for their ill child, while still maintaining their own health, should be explored further in future studies.

Low socioeconomic status is often mentioned as a predictor of severe socioeconomic consequences among parents of children with cancer (Kelada et al., 2020; Roser et al., 2019; Santacroce et al., 2018). Indeed, struggling financially before the child's diagnosis was discussed as an aggravating circumstance in the focus groups in this study as well, which forced parents to work even when they would have preferred to be with their child. Interestingly, however, was that being forced to work was not necessarily related to low socioeconomic status, but was often the case also for those with high income, as they had a lifestyle that required that they continued to have a high income (such as owning a large house with loans that had to be paid). Santacroce et al. (2020) made a similar observation in their study of fathers of children with cancer, where the unexpectedness of the financial hardship due to the child's illness caused severe distress among fathers who did not necessarily consider themselves financially vulnerable beforehand. Qualitative studies, like the present study, have an advantage in capturing effects like these, as consequences in terms of, for example, loss of income or employment can be considered in their specific context and life situation.

Noticeably, having a high-status job was often related to more flexibility in how to arrange one's work, thus enabling parents to work as much as necessary or desirable. However, the flexibility did sometimes come at the cost of feeling obliged to work when the parents would in fact rather have spent time with their child. Overall, type of job was emphasized as important in parents' ability to balance work and family, as was the attitude of the employer. Workplace characteristics, such as flexibility in work arrangement, as well as supervisory support, has been identified to impact work-family balance among parents with chronically ill children in previous studies as well (Brown, 2014; Brown \& Clark, 2017; Kish et al., 2020). In addition, both low work flexibility as well as work-tofamily conflict have been found to have a particularly negative effect on health among parents of seriously ill children (Song et al., 2014). How the knowledge of the facilitating role of employer can be implemented in reality, and thereby bridge the gap from research to practice, should be the focus of future studies.

An important conclusion to be drawn from the focus groups is that a long-term perspective is essential to 
understand the parents' struggle with balancing work and parenthood. As expected, the balance was radically disrupted when the child was diagnosed with cancer, and parents described an overall understanding and sympathy from people around them at that stage. However, parents expressed a frustration over the lack of understanding that the child's illness had consequences also long after end of treatment. Parents described how both the continued demanding care needs of the child, as well as their own reduced work ability due to impaired health, was met with annoyance from employers and colleagues, and ignorance from social authorities. On a group level, extent of care leave has not been found to impact income development (Hjelmstedt et al., 2021), but by using focus groups as source of data, we were able to show that many parents do in fact feel penalized by employers for their absence from work. Importantly, that some parents experienced being forced out of work, either directly or indirectly, is rather noteworthy in the Swedish context, where the protection of labour rights is heavily emphasized. The parents' fear of being excluded from the labour market, and consequently parts of the support system, cannot be disregarded.

Furthermore, the parents emphasized the importance of support in their ability to balance demands of work and family. In particular, the parents expressed feeling a lack of sufficient support and dissatisfaction with organization of support, especially in the long-term. Assessment of family financial burden has been put forth as a component in comprehensive psychosocial care for parents of children with cancer (Pelletier \& Bona, 2015), but this is not systematically assessed in the Swedish childhood cancer care. Further research is warranted to investigate in what sense the parents consider the support to be inadequate, and more specifically how the support from the healthcare can be improved in practice. Results from the study highlight that this is important not only in the acute treatment stages, but also in the long-term, in order for the parents not to end up in a situation where the socioeconomic situation constitute an additional burden for the families.

\section{Strengths and Limitations}

The interaction between participants in a focus group may constitute a risk of the data being influenced by participants not wanting to say something outside of the group norm (Morgan, 1997). To limit this risk, we emphasised to the participants that all experiences were of interest, and actively worked to ensure that all participants were included in the discussion. The participants were active in the discussion, and were eager to share their experiences as they expressed that they perceived the topic important and often overlooked.

The optimal number of participants in focus groups is disputed, and depends on the character of the topic and the involvement of the participants (Morgan, 1997). Our focus groups consisted of 2-5 participants, which could be considered as few. However, after conducting a few interviews, our assessment was that a maximum of five participants was appropriate. The participants had much to share, and the stories were often emotional. A larger group may have prevented the participants from getting the time needed to share their stories, and may have restricted the openness of the groups.

The focus groups were held with only mothers or only fathers to facilitate discussions of experiences that might be influenced by gender roles. To have homogenous groups in certain features, such as gender, is recommended to facilitate openness in the group (Morgan, 1997), and our assessment is that the division enabled the participants to reflect more freely.

The study fared well in capturing experiences from parents in a variety of socioeconomic and demographic contexts. However, as the parents themselves signed up to participate in the study, there is a risk that those who were interested in participating in the study were also those who had extreme experiences, thus making them less representative and impacting the transferability of the study (Graneheim \& Lundman, 2004). Nonetheless, the rich descriptions from the participants enabled the authors to gain an overall understanding of the experience of parenting a child with cancer and draw conclusions on the experience of balancing work and family.

When considering the transferability of the results, the national context should be taken into account. The ability to balance work and family when a child is seriously ill may differ depending on laws on labour rights, social benefits and the health care system, but also cultural factors, and these circumstances should be considered when interpreting the results to a larger setting. Although the participants are all parents of children with cancer, the results of the study are not necessarily limited to the experience of cancer, and could be considered somewhat transferable to parenting children with other serious illnesses as well.

\section{Conclusions}

Our results show that balancing work and parenthood when parenting a child with cancer entails several challenges. From initially after diagnosis focusing almost entirely on caring for the child, the importance of work as a welcome break and a positive counterbalance from the demanding parenting role becomes evident. The possibility for parents to balance work and parenthood is influenced by factors such as the pre-existing financial situation and the work characteristics and support from the employer. The influence of gender roles is evident, with parents experiencing the effects of expectations from others, as well as reinforced 
gender roles within couples. Importantly, while employers, social authorities, and even friends expect the parents' situation to get back to normal shortly after the acute stages of the disease trajectory, the child's illness continue to make a substantial mark in the parents' view of and ability to balance work and parenthood, both financially, practically, and emotionally, for a considerable period of time.

\section{Data Availability}

Data from this study cannot be made publicly available due to ethical constraints.

Acknowledgements The authors would like to gratefully acknowledge all the parents who participated in this study, as well as the Swedish Childhood Cancer Fund who assisted in the recruitment process.

Author Contributions All authors contributed to the study conception and design, as well as recruitment of participants. S.K.H., U.F. and A. L.N. conducted the focus group interviews. Primary analysis and coding of the data were performed by S.K.H. and E.H., and final analysis was performed by all authors. S.K.H. wrote the first draft of the paper. All authors contributed substantially to the writing and revising of the paper, read and approved the final version of the paper.

Funding This study has been financed by grants from the Swedish Childhood Cancer Fund (grant numbers PR2014-0072; PROJ10-048; PDS11/006), Karolinska Institutet KID funding (grant number 2-3591/ 2014), and Mary Béve Foundation for Childhood Cancer Research. Open access funding provided by Karolinska Institute.

\section{Compliance with Ethical Standards}

Conflict of Interest The authors declare no competing interests.

Ethical Approval This study was performed in line with the principles of the Declaration of Helsinki. Approval was granted by the Regional Ethical Review Board in Stockholm (2011/804-31/5; 2014/1634-32; 2019-03277).

Informed Consent Participants were given written and verbal information about the study. All participants in the study provided written informed consent.

Publisher's note Springer Nature remains neutral with regard to jurisdictional claims in published maps and institutional affiliations.

Open Access This article is licensed under a Creative Commons Attribution 4.0 International License, which permits use, sharing, adaptation, distribution and reproduction in any medium or format, as long as you give appropriate credit to the original author(s) and the source, provide a link to the Creative Commons license, and indicate if changes were made. The images or other third party material in this article are included in the article's Creative Commons license, unless indicated otherwise in a credit line to the material. If material is not included in the article's Creative Commons license and your intended use is not permitted by statutory regulation or exceeds the permitted use, you will need to obtain permission directly from the copyright holder. To view a copy of this license, visit http://creativecommons. org/licenses/by/4.0/.

\section{References}

Brown, T. J. (2014). Work family conflict among parents of atypically developing children: exploring the impact of worker, work and child factors. Journal of Child and Family Studies, 23, 854-862.

Brown, T. J., \& Clark, C. (2017). Employed parents of children with disabilities and work family life balance: a literature review. Child \& Youth Care Forum, 46, 857-976.

Clarke, N. E., McCarthy, M. C., Downie, P., Ashley, D. M., \& Anderson, V. A. (2009). Gender differences in the psychosocial experience of parents of children with cancer: a review of the literature. Psycho-Oncology, 18, 907-915.

Cousino, M. K., \& Hazen, R. A. (2013). Parenting stress among caregivers of children with chronic illness: a systematic review. Journal of Pediatric Psychology, 38(8), 809-828.

George, A., Vickers, M. H., Wilkes, L., \& Barton, B. (2008). Working and caring for a child with chronic illness: challenges in maintaining employment. Employee Responsibility and Rights Journal, 20, 165-176.

Gibbins, J., Steinhardt, K., \& Beinart, H. (2012). A systematic review of qualitative studies exploring the experience of parents whose child is diagnosed and treated for cancer. Journal of Pediatric Oncology Nursing, 29(5), 253-271.

Graneheim, U. H., \& Lundman, B. (2004). Qualitative content analysis in nursing research: concepts, procedures and measures to achieve trustworthiness. Nurse Education Today, 24, 105-112.

Granek, L., Rosenberg-Yunger, Z. R. S., Dix, D., Klaassen, R. J., Sung, L., Cairney, J., \& Klassen, A. F. (2012). Caregiving, single parents and cumulative stresses when caring for a child with cancer. Child: care, health and development, 40(2), 184-194.

Greenhaus, J. H., \& Beutell, N. J. (1985). Sources of conflict between work and family roles. The Academy of Management Review, 10 (1), 76-88.

Hiyoshi, A., Montgomery, S., Bottai, M., \& Hovén, E. I. (2018). Trajectories of income and social benefits for mothers and fathers of children with cancer: a national cohort study in Sweden. Cancer, 124(5), 1492-1500.

Hjelmstedt, S., Lindahl Norberg, A., Montgomery, S., Hed Myrberg, I., \& Hovén, E. (2017). Sick leave among parents of children with cancer - a national cohort study. Acta Oncologica, 56(5), 692-697.

Hjelmstedt, S., Montgomery, S., Nybergh, L., Hed Myrberg, I., Lindahl Norberg, A., \& Hovén, E. (2021). Division of childcare leave among parents of children with a serious illness. Journal of Family Issues, 42(6), 1308-1332.

Jansen, N. W. H., Kant, I. J., Kristensen, T. S., \& Nijhuis, F. J. N. (2003). Antecedents and consequences of work-family conflict: a prospective cohort study. Journal of Occupational and Environmental Medicine, 45(5), 479-491.

Kelada, L., Wakefield, C. E., Vetsch, J., Schofield, D., Sansom-Daly, U. M., Hetherington, K., O'Brien, T., Cohn, R. J., Anazodo, A., Viney, R., \& Zeppel, M. J. B. (2020). Financial toxicity of childhood cancer and changes to parents' employment after treatment completion. Pediatric Blood \& Cancer, 67(7), e28345.

Kish, A. M., Newcombe, P. A., \& Haslam, D. M. (2018). Working and caring for a child with chronic illness: a review of current literature. Child: Care, Health and Development, 44, 343-354.

Kish, A. M., Haslam, D. M., \& Newcombe, P. A. (2020). Child chronic illness and parent work-family conflict: investigating the experiences of working parents. Journal of Child and Family Studies, 29, 1312-1325.

Kukkola, L., Hovén, E., Cernvall, M., von Essen, L., \& Grönqvist, H. (2017). Perceptions of support among Swedish parents of children after end of successful cancer treatment: a prospective, longitudinal study. Acta Oncologica, 56(12), 1705-1711. 
Lewis, S., Kagan, C., \& Heaton, P. (2000). Dual-earner parents with disabled children family patterns for working and caring. Journal of Family Issues, 21(8), 1031-1060.

Lindahl Norberg, A., \& Steneby, S. (2009). Experiences of parents of children surviving brain tumour: a happy ending and a rough beginning. European Journal of Cancer Care, 18(4), 371-380.

Lindahl Norberg, A., Montgomery, S. M., Bottai, M., Heyman, M., \& Hovén, E. I. (2017). Short-term and long-term effects of childhood cancer on income from employment and employment status: a national cohort study in Sweden. Cancer, 123(7), $1238-1248$.

Ljungman, L., Hovén, E., Ljungman, G., Cernvall, M., \& von Essen, L. (2015). Does time heal all wounds? A longitudinal study of the development of posttraumatic stress symptoms in parents of survivors of childhood cancer and bereaved parents. PsychoOncology, 24, 1792-1798.

Long, K. A., \& Marsland, A. L. (2011). Family adjustment to childhood cancer: a systematic review. Clinical Child and Family Psychology Review, 14, 57-88.

Michel, G., Brinkman, T. M., Wakefield, C. E., \& Grootenhuis, M. (2020). Psychological outcomes, health-related quality of life, and neurocognitive functioning in survivors of childhood cancer and their parents. Pediatric Clinics of North America, 67(6), 1103-1134.

Molinaro, M. L., \& Fletcher, P. C. (2018). The balancing act: Mothers' experiences of providing care to their children with cancer. Journal of Pediatric Oncology Nursing, 35(6), 439-446.

Morgan, D. L. (1997). Focus groups as qualitative research. Qualitative Research Methods Series, Vol 16. 2nd ed. Thousand Oaks, California: SAGE Publications Inc.

Morris, L. A. (2014). The impact of work on the mental health of parents of children with disabilities. Family Relations, 63(1), $101-121$

National Board of Health and Welfare. (2018). Cancer i siffror 2018. Socialstyrelsen, 2018-6-10.

Oeffinger, K. C., Mertens, A. C., Sklar, C. A., Kawashima, T., Hudson, M. M., Meadows, A. T., Friedman, D. L., Marina, N., Hobbie, W., Kadan-Lottick, N. S., Schwartz, C. L., Leisenring, W., \& Robison, L. L., Childhood Cancer Survivor Study. (2006). Chronic health conditions in adult survivors of childhood cancer. The New England Journal of Medicine, 355(15), 1572-1582.

Pelchat, D., Lefebvre, H., \& Levert, M.-J. (2007). Gender differences and similarities in the experience of parenting a child with a health problem: current state of knowledge. Journal of Child Health Care, 11(2), 112-131.

Peikert, M. L., Inhestern, L., Krauth, K. A., Escherich, G., Rutkowski, S., Kandels, D., \& Bergelt, C. (2020). Returning to daily life: a qualitative interview study on parents of childhood cancer survivors in Germany. BMJ Open, 10, e033730.

Pelletier, W., \& Bona, K. (2015). Assessment of financial burden as a standard of care in pediatric oncology. Pediatric Blood \& Cancer, 62, S619-S631.
Pinquart, M. (2017). Parenting stress in caregivers of children with chronic physical condition - a meta-analysis. Stress and Health, 34, 197-207.

Rodriguez, E.M., Dunn, M.J., Zuckerman, T., Vannatta, K., Gerhardt, C.A., \& Compas, B.E. (2012). Cancer-related sources of stress for children with cancer and their parents. Journal of Pediatric Psychology, 37(2), 185-197.

Roser, K., Erdmann, F., Michel, G., Winther, J. F., \& Mader, L. (2019). The impact of childhood cancer on parents' socio-economic situation-a systematic review. Psycho-Oncology, 28(6), 1207-1226.

Santacroce, S. J., Tan, K. R., \& Killela, M. K. (2018). A systematic scoping review of the recent literature (similar to 2011-2017) about the costs of illness to parents of children diagnosed with cancer. European Journal of Oncology Nursing, 35, 22-32.

Santacroce, S. J., Killela, M. K., Kerr, G., Leckey, J. A., \& Kneipp, S. M. (2020). Fathers' psychological responses to pediatric cancer-induced financial distress. Pediatric Blood \& Cancer, 67, e28281.

Social Insurance Code. 2010a. (Socialförsäkringsbalken) 2010:110, Chapter 13.

Social Insurance Code. 2010b. (Socialförsäkringsbalken) 2010:110, Chapter 22.

Song, J., Mailick, M. R., \& Greenberg, J. S. (2014). Work and health of parents of adult children with serious mental illness. Family Relations, 63(1), 122-134.

Statistics Sweden. (2020). Women and men in Sweden 2020.

Sulkers, E., Tissing, W. J. E., Brinksma, A., Roodbol, P. F., Kamps, W. A., Stewart, R. E., Sanderman, R., \& Fleer, J. (2015). Providing care to a child with cancer: a longitudinal study on the course, predictors, and impact of caregiving stress during the first year after diagnosis. Psycho-Oncology, 24, 318-324.

Swedish Social Insurance Agency. (2013). De jämställda föräldrarna. Social Insurance Report 2013:8.

Tan, R., Koh, S., Wong, M. E., Rui, M., \& Shorey, S. (2020). Caregiver stress, coping strategies, and support needs of mothers caring for their children who are undergoing active cancer treatments. Clinical Nursing Research, 29(7), 460-468.

Vrijmoet-Wiersma, C. M. J., van Klink, J. M. M., Kolk, A. M., Koopman, H. M., Ball, L. M., \& Egeler, R. M. (2008). Assessment of parental psychological stress in pediatric cancer: a review. Journal of Pediatric Psychology, 33(7), 694-706.

Wakefield, C. E., McLoone, J. K., Evans, N. T., Ellis, S. J., \& Cohn, R. J. (2014). It's more than dollars and cents: the impact of childhood cancer on parents' occupational and financial health. Journal of Psychosocial Oncology, 32(5), 602-621.

West, C., \& Zimmerman, D. H. (1987). Doing gender. Gender and Society, 1(2), 125-151.

Wikman, A., Mattsson, E., von Essen, L., \& Hovén, E. (2018). Prevalence and predictors of symptoms of anxiety and depression, and comorbid symptoms of distress in parents of childhood cancer survivors and bereaved parents five years after end of treatment or a child's death. Acta Oncologica, 57(7), 950-957. 